\title{
PENGARUH HUMAN CAPITAL DAN GENDER TERHADAP KUALITAS AUDITOR PADA KANTOR AKUNTAN PUBLIK DI MEDAN
}

\author{
Bintang Wiratama Kusuma Putra ${ }^{1}$ Azizul Kholis ${ }^{2}$, Esa Setiana ${ }^{3}$ \\ Universitas Negeri Medan ${ }^{1,2,3}$ \\ Azizulkholis@unimed.ac.id ${ }^{2}$
}

\begin{abstract}
Abstrak
Penelitian ini mengkaji tentang kualitas auditor dalam mengeluarkan opini terhadap laporan keuangan. Hasil opini yang dikeluarkan auditor dapat mempengaruhi nilai suatu perusahaan. Penelitian ini bertujuan untuk menguji hubungan Human Capital dan Gender terhadap kualitas auditor pada Kantor Akuntan Publik (KAP) di Medan. Populasi dalam penelitian ini adalah auditor yang bekerja pada Kantor Akuntan Publik (KAP) di Medan. Dengan teknik pengumpulan data melalui keusioner diperoleh 36 sampel. Data yang diperoleh merupakan data primer pada kantor Akuntan Publik (KAP) di Medan. Variabel penelitian ini terdiri dari Kualitas Auditor sebagai variabel terikat dan Human Capital dan Gender sebagai variabel bebas. Teknik analisis data yang digunakan dalam penelitian ini adalah SMART Partial Least Square (PLS). Hasil penelitian ini menunjukan bahwa variabel Human Capital secara partial tidak berpengaruh dan signifikan terhadap Kualitas Auditor. Variabel Gender secara partial berpengaruh dan signifikan terhadap Kualitas Auditor. Sedangkan secara simultan, Variabel Human Capital dan Gender terhadap Kualitas Auditor. Kesimpulan penelitian ini adalah secara partial variabel Gender berpengaruh terhadap Kualitas Auditor sedangkan variabel Human Capital tidak berpengaruh dan signifikan. Variabel Human Capital dan Gender tidak berpengaruh secara simultan terhadap kualitas auditor pada Kantor Akuntan Publik (KAP) di Medan.
\end{abstract}

Kata Kunci: Human Capital, Gender, Auditor Quality 


\section{Pendahuluan}

Ikatan Akuntan Indonesia (IAI) menyatakan bahwa audit yang dilakukan auditor dikatakan berkualitas, jika memenuhi standar auditing dan standar pengendalian mutu. Selanjutnya menurut De Angelo (1981) dalam Kusharyanti (2003:25) mendefinisikan kualitas audit sebagai kemungkinan (probability) dimana auditor akan menemukan dan melaporkan pelanggaran yang ada dalam sistem akuntansi klien.

Laporan keuangan yang dilaporkan oleh perusahaan belum bisa menjamin kebenaran dan kehandalannya. Untuk itu, audit perlu dilakukan terhadap laporan-laporan keuangan tersebut. Orang yang melakukan audit adalah auditor atau disebut juga auditor eksternal. Auditor adalah salah satu pihak yang berkaitan langsung dengan laporan keuangan. Auditor akan membuat suatu laporan keuangan lebih berkualitas dan handal. Auditor bertugas menjadi "penilai" suatu laporan keuangan. Auditor lah yang menentukan wajar atau tidaknya laporan keuangan yang diterbitkan oleh suatu entitas / perusahaan.

Auditor bekerja sebagai satu kesatuan pada suatu Kantor Akuntan Publik atau biasa disebut KAP. Menurut UU No. 5 Tahun 2011 tentang Akuntan Publik, KAP dibagi menjadi KAP nasional dan KAP Asing. Suatu KAP akan mengaudit suatu laporan keuangan yang telah dibuat kliennya. Auditor dalam KAP akan ditugaskan memeriksa laporan keuangan tersebut apakah telah sesuai dengan standar penyusunan dan disajikan sesuai kenyataan yang dimiliki oleh perusahaan. Setelah auditor tersebut selesai memeriksa laporan keuangan, auditor tersebut akan memberikan hasil pemeriksaannya dan memberikan keputusan / opini apakah laporan keuangan tersebut dibuat dengan wajar atau tidak.

Hasil opini tidak dapat dikeluarkan dengan begitu saja, penghitungan dan pertimbangan yang baik harus dilakukan agar suatu KAP tidak kehilangan kredibilitasnya. KAP harus memiliki modal intelektual (intellectual capital) yang baik agar tetap mampu berkembang dan bersaing sebagai suatu bidang usaha. Menurut Zurnali (2008), modal intektual (intellectual capital) adalah semua yang merupakan asset dan sumber daya non-tangible atau non-physical dari sebuah organisasi. Salah satu bagian modal intelektual adalah modal manusia (human capital).

Modal manusia (human capital) adalah modal yang dimiliki manusia secara personal yang bekerja didalam suatu bidang usaha. Apalagi bagi suatu KAP, dimana membutuhkan banyak kemampuan dari auditor sebagai manusia untuk memperhitungkan dan mempertimbangkan bukti-bukti yang didapatnya dari pemeriksaan laporan keuangan kliennya. Cheng dan Liu (2009) mengatakan, KAP harus memastikan bahwa mereka memiliki orang-orang yang memiliki kompetensi dan karakter professional sehingga mereka dapat bekerja sesuai dengan standar, peraturan, dan harapan publik. KAP harus lebih memperhatikan kualitas dari auditornya. Kualitas auditor menjadi peranan penting bagi bertahan dan berkembangnya suatu KAP.

Selain mengenai human capital dalam KAP, isu meningkatnya jumlah auditor wanita secara pesat pada masa kini membuat gender menarik untuk diteliti. Keadaan tersebut menunjukkan bahwa telah terjadi perubahan didalam budaya atau kebiasaan masyarakat di Indonesia. Indonesia mulai menjadi negara yang menjunjung untuk adanya kesetaraan gender. Terutama pada profesi auditor di KAP, wanita tidak hanya menjabat sebagai auditor junior tetapi juga banyak dari wanita yang menjabat sebagai senior, manajer, bahkan partner dalam suatu KAP.

Selain itu, variabel gender ditambahkan dalam penelitian karena masih banyaknya pertentangan hasil penelitian (research gap). Menurut Jamilah (2007) dalam Salsabila (2011), gender diduga menjadi salah satu faktor level individu yang turut mempengaruhi kualitas hasil kerja auditor internal. Begitu pun pendapat dari Ruegger dan King (1992) dalam Iswari dan Kusuma (2013) menyatakan wanita umumnya memiliki tingkat pertimbangan moral yang lebih tinggi daripada pria. Wibawa (2010) menyatakan bahwa variabel gender mempengaruhi hasil kualitas audit pada KAP Yogyakarta dan Semarang. Kushasyandita (2012) juga menyatakan bahwa variabel gender berpengaruh positif terhadap ketepatan pemberian opini secara langsung pada Kantor Akuntan Publik big four.

Meski banyak penelitian yang menyatakan bahwa gender mempengaruhi kinerja auditor dalam memberikan keputusan. Salsabila (2011) menyatakan bahwa gender tidak berpengaruh terhadap hasil 
kerja auditor internal sesuai penelitian yang dilakukannya terhadap auditor pada Inspektorat Wilayah Provinsi DKI Jakarta. Dari beberapa penelitian yang telah dilakukan di Indonesia sebelumnya dan penelitian Cheng dan Liu (2009) yang dijadikan jurnal acuan dalam penyusunan penelitian, penelitian ini memiliki beberapa perbedaan. Perbedaan tersebut antara lain terletak pada responden, lokasi, dan cara pengambilan data serta penambahan variabel gender ke dalam penelitian. Cara pengambilan data berbeda karena Cheng dan Liu (2009) mendapatkan data dari laporan tahunan mengenai KAP yang diterbitkan di Taiwan, sedangkan di Indonesia laporan tersebut tidak/belum dilakukan.

\section{Kerangka Teoritis dan Pengembangan Hiotesis}

\subsection{Teori Motivasi}

Teori motivasi yang dikemukakan oleh Abraham Maslow menyatakan bahwa manusia di tempat kerjanya dimotivasi oleh suatu keinginan untuk memuaskan sejumlah kebutuhan yang ada dalam diri seseorang (Maslow dalam Sunyoto, 2012). Menurut Maslow (1960) menyatakan bahwa kebutuhan motivasi seseorang dapat disusun berdasarkan sebuah hierarki. Maslow menyusun lima tingkat hierarki kebutuhan manusia yang tergambar dalam gambar 1 yaitu :

Tingkat kebutuhan paling tinggi menurut Maslow.

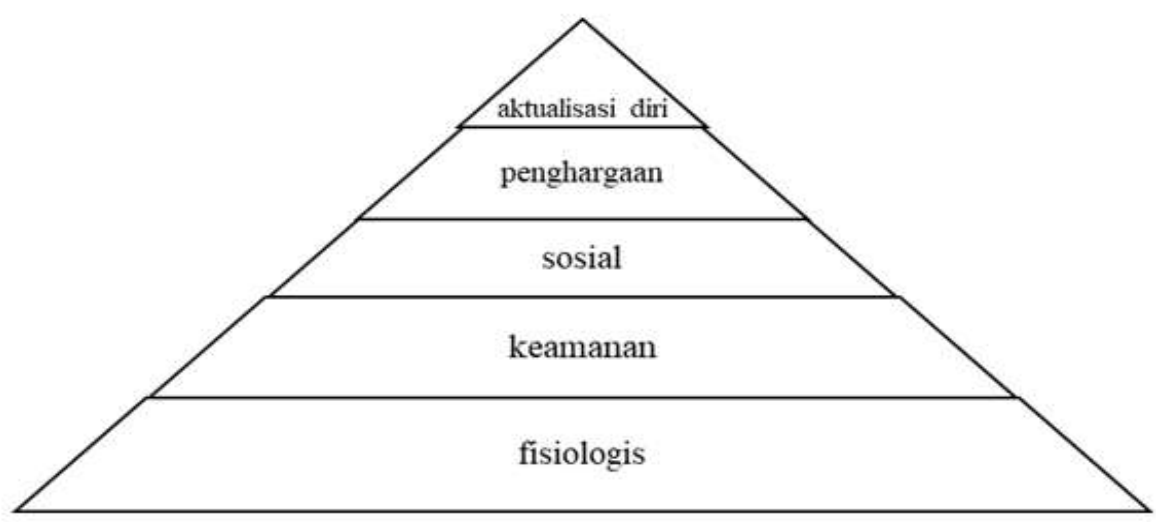

Gambar I

\subsection{Kualitas Auditor}

Definisi kualitas menurut Kamus Besar Bahasa Indonesia (KBBI) yaitu tingkat/kadar baik buruknya sesuatu. Secara umum, kualitas auditor berarti kadar baik buruknya auditor dalam melaksanakan kegiatan audit. Kini, audit memiliki peran penting tidak hanya di dunia perekonomian saja, tetapi juga pada pemerintahan dan pada masyarakat. Hasil audit akan mempengaruhi keputusan yang diambil oleh suatu pihak.

Ada beberapa macam jenis auditor, yaitu:

\section{Auditor Pemerintah}

Auditor pemerintah adalah auditor yang bertugas melakukan audit atas keuangan pada instansiinstansi pemerintah. Di Indonesia, auditor pemerintah dibagi menjadi dua, yaitu auditor internal pemerintah dan auditor eksternal pemerintah. Auditor internal pemerintah adalah Badan Pengawasan Keuangan dan Pembangunan (BPKP), Inspektorat Jenderal Departemen / LPND, dan Badan Pengawasan Daerah. Sedangkan auditor eksternal pemerintah adalah Badan Pemeriksa Keuangan (BPK). BPK bekerja diluar perintah dan tidak tunduk pada pemerintah sehingga diharapkan BPK dapat bersikap independen.

\section{Auditor Internal}


Auditor internal adalah auditor yang bekerja pada suatu perusahaan. Auditor internal bertugas untuk membantu manajemen perusahaan dan memeriksa kekurangan yang ada pada perusahaan untuk kemudian dapat membuat perusahaan menjadi lebih baik. Auditor internal merupakan karyawan perusahaan, ia termasuk bagian dari suatu perusahaan.

\section{Auditor Independen}

Auditor independen adalah adalah auditor yang bekerja pada Kantor Akuntan Publik (KAP). Auditor independen bertugas sebagai pemeriksa laporan keuangan yang diterbitkan oleh perusahaan yang go-public, perusahaan besar dan kecil serta organisasi lain yang tidak bertujuan mencari laba

\subsection{Human Capital}

Human Capital berasal dari kata human yaitu manusia dan capital yaitu modal yang secara harfiah berarti manusia sebagai modal. Modal yang dimaksud adalah nilai tambah dalam diri manusia. Teori human capital diperkenalkan oleh Theodore W.Schultz tahun 1961 sehingga peletak dasar teori human capital. Menurut Badan Pendidikan dan Pelatihan Keuangan dalam Departemen Keuangan, Schulz (1961) dalam pidatonya yang berjudul invesment in Human Capital menyatakan bahwa manusia merupakan suatu bentuk modal atau kapital sebagaimana bentuk-bentuk kapital lainnya seperti mesin, teknologi, uang dan material. Oleh karenanya, Schultz merupakan peletak dasar dari human capital (Savitri,2013).

\subsection{Gender}

Gender adalah berbagai karakteristik yang berkaitan dengan, dan membedakan antara, maskulinitas dan feminitas. Karakteristik tersebut mengarah pada jenis kelamin secara biologi dimana maskulin adalah pria dan feminin adalah wanita. Dalam sosiologi, gender tidak hanya mengenai jenis kelamin, tetapi juga peran sosial dan identitasnya di dalam masyarakat.

\subsection{Hipotesis}

H1 : Human capital (yang diukur dengan tingkat pendidikan, pengalaman kerja, sertifikasi profesional dan CPD) berpengaruh terhadap kualitas auditor.

H2 : Gender berpengaruh terhadap kualitas auditor.

H3 : Human capital dan Gender berpengaruh terhadap kualitas auditor.

\section{Metode Penelitian}

Penelitian ini dilakukan pada Kantor Akuntan Publik (KAP) yang ada di Kota Medan, Penelitian ini dilaksanakan pada bulan Desember 2019 sampai dengan selesai. Populasi dalam penelitian ini adalah auditor-auditor pada KAP yang ada di Kota Medan. Metode pengumpulan data adalah melalui penyebaran kuisioner, dengan menggunakan metode simple random sampling sehingga setiap anggota populasi memiliki kesempatan yang sama untuk menjadi sampel. Data dalam penelitian ini adalah data primer yang bersumber dari jawaban responden atas pertanyaan yang diajukan melalui kuisioner

\section{Hasil}

4.1 Pengujian Hipotesis

Tabel 1

Path Coefficient- Hipotesis 1 dan 2

\begin{tabular}{lccccc}
\hline & $\begin{array}{c}\text { Original } \\
\text { Sample }\end{array}$ & $\begin{array}{c}\text { Sample } \\
\text { Mean }\end{array}$ & $\begin{array}{c}\text { Standard } \\
\text { Deviation }\end{array}$ & $\begin{array}{c}\text { T } \\
\text { Statistics }\end{array}$ & $\begin{array}{c}\boldsymbol{P} \\
\text { Values }\end{array}$ \\
\hline $\begin{array}{l}\text { Human Capital }(\mathrm{X} 1) \rightarrow \\
\text { Kualitas Audiotor (Y) }\end{array}$ & 0.021 & 0.000 & 0.148 & 0.133 & 0.894 \\
$\begin{array}{l}\text { Gender (X2) } \rightarrow \text { Kualitas } \\
\text { Audiotor (Y) }\end{array}$ & 0.856 & 0.823 & 0.253 & 3.431 & 0.001 \\
\hline
\end{tabular}

Berdasarkan hasil pengujian hipotesis pada penelitian ini adalah sebagai berikut: 
1. Variabel human capital (X1) tidak berpengaruh secara positif dan signifikan terhadap kualitas audit (Y) dengan nilai P-value 0,894 >0,05 dan $\mathrm{t}$ hitung 0,133 < t tabel 2,010 (tabel terlampir).

2. Variabel gender (X2) berpengaruh secara positif dan signifikan terhadap kualitas audit (Y) dengan nilai P-value 0,001 <0,05 dan t hitung 3,431 > t tabel 2,010 (tabel terlampir).

\section{Tabel 2}

Path Coefficient- Hipotesis 3

\begin{tabular}{|c|c|c|c|c|c|}
\hline & $\begin{array}{l}\text { Original } \\
\text { Sample }\end{array}$ & $\begin{array}{c}\text { Sample } \\
\text { Mean }\end{array}$ & $\begin{array}{l}\text { Standard } \\
\text { Deviation } \\
\end{array}$ & $\begin{array}{c}F \\
\text { Statistics } \\
\end{array}$ & $\begin{array}{c}P \\
\text { Values }\end{array}$ \\
\hline Human Capital (X1) $\rightarrow$ & & 0.032 & 0.052 & 0.012 & 0.991 \\
\hline Kualitas Audiotor (Y) & 0.001 & & & & \\
\hline $\begin{array}{l}\text { Gender }(\mathrm{X} 2) \rightarrow \text { Kualitas } \\
\text { Audiotor }(\mathrm{Y})\end{array}$ & 1.045 & 1.259 & 0.692 & 1.511 & 0.131 \\
\hline
\end{tabular}

Berdasarkan hasil pengujian simultan dibawah ini diketahui bahwa human capital dan gender memiliki nilai signifikansi $>0,05$ dan nilai $\mathrm{f}$ hitung $<2,010$ ( $\left.\mathrm{f}_{\text {tabel }}\right)$. Dengan demikian, dapat disimpulkan bahwa human capital dan gender tidak berpengaruh secara simultan (bersamaan) terhadap kualitas auditor.

\subsection{Pembahasan Hasil Penelitian \\ Pengaruh Human Capital Terhadap Kualitas Auditor}

Berdasarkan hasil pengujian, diperoleh hasil bahwa variabel Human Capital tidak berpengaruh positif dan signifikan terhadap kualitas auditor. Hal ini terlihat dari nilai signifikansinya lebih besar dar 0,05 yaitu 0,894. Hal ini berarti bahwa Human Capital tidak memiliki pengaruh yang relevan dan tidak signifikan terhadap kualitas auditor.

Hasil penelitian ini tidak sejalan dengan teori Human Capital yang menyatakan bahwa manusia merupakan suatu bentuk modal atau kapital, sebagaimana bentuk-bentuk kapital lainnya seperti mesin, teknologi, uang dan material. Hal ini menujukkan bahwa Human Capital yang dirumuskan menggunakan tingkat pendidikan, pengalaman kerja, sertifikat profesional, Continuing Professional Development (CPD) tidak dapat menghalangi baiknya kualitas auditor pada setiap Kantor Akuntan Publik (KAP) yang ada di Kota Medan.

\section{Pengaruh Gender Terhadap Kualitas Auditor}

Berdasarkan hasil pengujian, diperoleh hasil bahwa variabel Gender berpengaruh positif dan signifikan terhadap kualitas auditor. Hal ini terlihat dari nilai signifikansinya lebih kecil dari 0,05 aitu 0,001 , seta nilai $\mathrm{t}$ hitung 3,431 > t tabel 2,010. Hal ini menunjukkan bahwa Gender berpengaruh secara relevan dan signifikan terhadap kualitas auditor.

Secara teoretis, gender merupakan sifat yang melekat pada kaum laki-laki maupun perempuan yang dikonstruksi secara sosial maupun kultural (Fakih, 2003). Teori gender diturunkan dari pemikiran-pemikiran dan teori sosial. Pada mulanya dikenal dua aliran teori, yaitu teori nuture dan teori nature. Kemudian dikembangkan teori bersifat kompromistis yang disebut teori keseimbangan atau teori equilibrium (Siswanto, 2008) dalam Agustianto (2013). Menurut teori nuture, perbedaan perempuan dan laki-laki adalah hasil kontruksi sosial budaya, sehingga menghasilkn peran dan tugas yang berbeda.

Teori nature menjelaskan perbedaan perempuan dan laki-laki adalah kodrat, sehingga harus diterima. Sedangkan teori equilibrium menekankan pada konsep kemitraan dan keharmonisan dalam hubungan antara perempuan dan laki-laki. Perempuan pada umumnya memiliki tingkat pertimbangan moral yang lebih tinggi daripada pria (Ruegger \& King dalam Jamilah, et. al., 2007). Pertimbangan moral yang dimaksudkan adalah sebagai langkah pengambilan keputusan dan informasi dalam mengaudit perusahaan klien. Pengambilan keputusan harus didukung oleh informasi yang memadai. Laki-laki dalam pengolahan informasi tersebut biasanya tidak menggunakan seluruh informasi yang tersedia sehingga keputusan yang diambil kurang komprehensif dan kualitas hasil kerjanya kurang baik. Sedangkan perempuan, mereka dalam mengolah informasi cenderung lebih teliti dengan menggunakan informasi yang lebih lengkap dan mengevaluasi kembali informasi tersebut dan tidak gampang menyerah (Meyer \& Levy dalam Jamilah (2007).

Perempuan relatif lebih efisien dibandingkan laki-laki dalam mendapat akses informasi. Selain itu, kaum wanita juga memiliki daya ingat yang lebih tajam terhadap suatu informasi baru dibandingkan 
kaum pria dan demikian halnya kemampuan dalam mengolah informasi lebih hati-hati sehingga dalam membuat keputusan judgment lebih tepat dibandingkan kaum pria. Kualitas audit sangat penting karena dengan kualitas audit yang tinggi maka akan dihasilkan laporan keuangan yang dapat dipercaya sebagai dasar pengambilan keputusan.

Secara empiris hasil penelitian ini konsisten dengan penelitian yang dilakukan oleh Wibawa (2010), yang menyatakan bahwa gender berpengaruh signifikan terhadap kualitas audit. Penelitian ini sejalan dengan penelitian yang dilakukan oleh Kusumayanti (2014), yang menyatakan bahwa terdapat pengaruh positif dan signifikan antara gender terhadap kualitas hasil kerja audit internal.

\section{Pengaruh Human Capital dan Gender Kualitas Auditor}

Berdasakan hasil pengujian, diperoleh bahwa nilai signifikansi $>0,05$ dan nilai $\mathrm{f}$ hitung $<2,010$ (ftabel). Dari nilai tersebut, maka secara bersama-sama variabel independen yaitu Human Capital dan Gender tidak berpengaruh positif dan signifikan terhadap varaibel dependen yaitu kualitas auditor.

\section{Kesimpulan dan saran}

\subsection{Kesimpulan}

Penelitian ini bertujuan untuk mengetahui variabel-variabel yang menentukan Kualitas Auditor pada Kantor Akuntan Publik (KAP) di Kota Medan sebanyak 36 sampel. Berdasarkan hasil analisis data yang telah diuji, dari tiga hipotesis yang diajukan hanya satu hiptesis yang diterima. Maka dapat di peroleh kesimpulan sebagai berikut:

1. Berdasarkan hasil pengujian hipotesis pertama variabel Human Capital tidak berpengaruh terhadap kualitas auditor pada Kantor Akuntan Publik (KAP) di Kota Medan dengan nilai signifikan sebesar $(0,894>0,05)$ dan ( $\mathrm{t}$ hitung $0,133<\mathrm{t}$ tabel 2,010). Hal ini menujukkan bahwa Human Capital yang dirumuskan menggunakan tingkat pendidikan, pengalaman kerja, sertifikat profesional, Continuing Professional Development (CPD) tidak dapat menghalangi baiknya kualitas auditor pada setiap Kantor Akuntan Publik (KAP) yang ada di Kota Medan.

2. Berdasarkan hasil pengujian hipotesis kedua variabel Gender berpengaruh terhadap kualitas auditor pada Kantor Akuntan Publik di Medan dengan nilai signifikan sebesar $(0,001<0,05)$ dan t hitung $(3,431>\mathrm{t}$ tabel 2,010). Hal ini menunjukkan bahwa Gender berpengaruh secara relevan dan signifikan terhadap kualitas auditor.

3. Berdasarkan hasil pengujian hipotesis ketiga variabel human capital dan gender secara bersamasama tidak berpengaruh terhadap kualitas auditor pada kantor akuntan publik di medan dengan nilai signifikan sebesar $>0,05$ dan nilai ( $\mathrm{f}$ hitung $<2,010 \mathrm{f}_{\text {tabel }}$ ).

\subsection{Saran}

Berdasarkan penelitin yang dilakukan, disadari masih terdapat banyak keterbatasan. Sehingga diberikan beberapa saran untuk pengembangan penelitian berikut.

1. Untuk peneliti selanjutnya, sebaiknya menggunakan metode lain yang lebih efektif sebab penelitian ini menggunakan metode survey melalui kuesioner dimana jawaban yang diberikan merupak representatif dari kondisi serta kinerja yang ada pada kantor akuntan publik tersebut, seingga kesimpulan yang diambil hanya berdasarkan pada data yang dikumpulkan melalui penggunaan instrumen secara tertulis.

2. Diharapkan untuk menambah faktor-faktor lain yang mempengaruhi kualitas auditor antara lain komunikasi dan komitmen organisasi. Kedua faktor ini kemungkinan mempunyai pengaruh positif terhadap kualitas auditor.

3. Diharapkan untuk menambah sampel yang digunakan agar dapat mewakili populasi secara keseluruhan dalam menentukan pengaruh positif pada kualitas auditor.

\section{Referensi}

Cheng, Yu-Shu., Yi-Pei Liu, dan Chu-Yang Chien. 2009. "The association between auditor quality and human capital” Managerial Auditing Journal, Vol. 24, No. 6, H. 523 - 541.

Fahmi Ahmad Riyadi, Endang kiswara. 2015. "pengaruh human capital dan gender terhadap kualitas auditor pada kantor akuntan publik di indonesia". JOURNAL OF ACCOUNTING volume 4. 
Ghozali, Imam. 2016. Structural Equation Modeling : Metode Alternatif dengan Partial Least Square. Edisi 4. Semarang: Badan Penerbit Universitas Diponegoro.

Ikhsan, Arfan, dkk. 2014. Metodologi Penelitian Bisnis. Bandung: Cipta pustaka Media.

Iswari, Tabita Indah. dan Indra Wijaya Kusuma. 2013. "The Effect of Organizational-Professional Conflict towards Professional Judgement by Public Accountant Using Personality Type, Gender, and Locus of Contol as Moderating Variables" Review of Integrative, Business, and Economics Research, Vol. 2(2), H. $434-448$.

Kusumayanti, P. T. 2014. Pengaruh Akuntabilitas, Pengetahuan Audit dan Gender terhadap Kualitas Hasil Kerja Auditor Internal (Studi pada Badan Inspektorat Kabupaten Buleleng dan Kabupaten Bangli). e-Journal S1 Ak Universitas Pendidikan Ganesha. Volume: 2 No. 1.

Kushasyandita, RR. Sabhrina. 2012. Pengaruh Pengalaman, Keahlian, Situasi Audit, Etika, dan Gender terhadap Ketepatan Pemberian Opini Auditor melalui Sketisisme Profesional Auditor. Fakultas Ekonomi, Universitas Diponegoro.

Lefrandi. 2012. "Teori Motivasi: Hierarki Kebutuhan Berdasarkan Perspektif Maslow". https://lefrandi.wordpress.com/2012/12/14/teori-motivasi-hierarki-kebutuhan-manusiaberdasarkan-perspektif-maslow/. Diakses tanggal 21 Januari 2015.

Ongkorahardjo Martina Dwi Puji Astri,Susanto Antonius,Rachmawati Dyna. 2008. "Analisis Pengaruh Human Capital Terhadap Kinerja Perusahaan (Studi Empiris pada Kantor Akuntan Publik di Indonesia)”. JURNAL AKUNTANSI DAN KEUANGAN, VOL. 10, NO. 1.

Pradita, Rima Dewi. 2010. "Hubungan antara Kualitas Auditor dan Human Capital di Badan Pemeriksa Keuangan (BPK) dan Badan Pengawas Keuangan dan Pembangunan (BPKP)". Fakultas Ekonomi, Universitas Diponegoro.

Salsabila, Ainia. 2011. "Pengaruh Akuntabilitas, Pengetahuan Audit, dan Gender terhadap Kualitas Hasil Kerja Auditor Internal” Jurnal Telaah \& Riset Akuntansi, Vol. 4, No. 1 Juli 2011, H. 155 175.

Sari elisa,dwiarti lina. 2018. "Pendekatan hierarki abraham maslow pada prestasi kerja karyawan pt.madubaru (pg madukismo) yogyakarta". jpsb vol.6 no 1.

Savitri, Oneal. 2013. "Pengaruh Human Capital terhadap Kualitas Auditor pada Kantor Akuntan Publik di Semarang”. Fakultas Ekonomi, Universitas Diponegoro.

Sekaran, Uma. 2003. Research Methods For Bussiness: A Skill Building Approach. Edisi 4. New York: John Wiley \& Sons, Inc.

Wibawa, Anggi. 2010. "Pengaruh Gender, Kompetensi, dan Independensi terhadap Kualitas Audit dengan Etika Auditor sebagai Variabel Moderasi”. Fakultas Ekonomi, Universitas Muhammadiyah Yogyakarta. 